\title{
Review on comparative efficacy of bevacizumab, panitumumab and cetuximab antibody therapy with combination of FOLFOX-4 in KRAS-mutated colorectal cancer patients
}

\author{
Surajit Pathak ${ }^{1}$, Sushmitha S ${ }^{1}$, Antara Banerjee ${ }^{1}$, Francesco Marotta $^{2}$, Madhumala \\ Gopinath $^{1}$, Ramachandran Murugesan ${ }^{1}$, Hong Zhang ${ }^{3}$, Bhavani ${ }^{1}{ }^{1}$, Agnishwar \\ Girigoswami ${ }^{1}$, Jose Sollano ${ }^{4}$ and Xiao-Feng Sun ${ }^{5}$ \\ ${ }^{1}$ Faculty of Allied Health Sciences, Chettinad Hospital and Research Institute (CHRI), Chettinad Academy of Research and \\ Education (CARE), Kelambakkam, Chennai, India \\ ${ }^{2}$ ReGenera Research Group for Aging-Intervention, Milano, Italy and San Babila Clinic, Healthy Aging Unit by Genomics \\ and Biotechnology, Milano, Italy \\ ${ }^{3}$ School of Medicine, Orebro University, Örebro, Sweden \\ ${ }^{4}$ Gastroenterology Department, University of Santo Tomas, Manila, The Philippines \\ ${ }^{5}$ Department of Oncology and Department of Clinical and Experimental Medicine, Linköping University, Linköping, Sweden \\ Correspondence to: Xiao-Feng Sun, email: xiao-feng.sun@liu.se \\ Surajit Pathak, email: surajit.pathak@gmail.com
}

Keywords: colorectal cancer; KRAS; bevacizumab; panitumumab; cetuximab

Received: October 15, $2016 \quad$ Accepted: October 11, $2017 \quad$ Published: November 16, 2017

Copyright: Pathak et al. This is an open-access article distributed under the terms of the Creative Commons Attribution License 3.0 (CC BY 3.0), which permits unrestricted use, distribution, and reproduction in any medium, provided the original author and source are credited.

\section{ABSTRACT}

Colorectal cancer, fourth leading form of cancer worldwide and is increasing in alarming rate in the developing countries. Treating colorectal cancer has become a big challenge worldwide and several antibody therapies such as bevacizumab, panitumumab and cetuximab are being used with limited success. Moreover, mutation in KRAS gene which is linked with the colorectal cancer initiation and progression further interferes with the antibody therapies. Considering median progression free survival and overall survival in account, this review focuses to identify the most efficient antibody therapy in combination with chemotherapy (FOLFOX-4) in KRAS mutated colorectal cancer patients. The bevacizumab plus FOLFOX-4 therapy shows about 9.3 months and 8.7 months of progression free survival for KRAS wild and mutant type, respectively. The overall survival is about $\mathbf{3 4 . 8}$ months for wild type whereas for the mutant it is inconclusive for the same therapy. In comparison, panitumumab results in better progression-free survival which is about ( 9.6 months) and overall survival is about (23.9 months) for the wild type KRAS and the overall survival is about 15.5 months for the mutant KRAS. Cetuximab plus FOLFOX-4 therapy shows about 7.7 months and $\mathbf{5 . 5}$ months of progression-free survival for wild type KRAS and mutant type, respectively. Thus, panitumumab shows significant improvement in overall survival rate for wild type KRAS, validating as a cost effective therapeutic for colorectal cancer therapy. This review depicts that panitumumab along with FOLFOX-4 has a higher response in colorectal cancer patients than the either of the two monoclonal antibodies plus FOLFOX-4.

\section{INTRODUCTION}

Carcinogenesis is a process containing numerous steps that arise from the combination of mutations in oncogenes or tumor suppressor genes or epigenetic changes in DNA such as methylation [1]. An epigenetic factor such as abnormal DNA methylation of tumor suppressor/promoter plays a major part in the evolution of colorectal cancer (CRC) [2]. CRC is considered to be the most significant cause of cancer death worldwide. 
In migrant populations, it has been demonstrated that populations shifting from low- to high-risk countries are more prone to an increased cancer risk, suggesting that exposure to confined environment may have the capacity to have an effect on CRC [1]. Globally, CRC is one of the most prevalent types of cancers in developed countries. Frequency rate of $\mathrm{CRC}$ varies widely in different geographical areas, with fewer occurrences in Asia, Africa and parts of Latin America, but with high occurrence in Northern Europe, Australia, New Zealand and U.S. Epidemiological studies show specific components such as dietary fat and red meat to be risk factors in CRC pathogenesis [1]. Even though surgery remains the therapeutic modality for $\mathrm{CRC}$, radiotherapy has shown a survival advantage over surgery with debatable reasons [3]. These outcomes further raised the question on specific application of RT and chemotherapy. Now, the main aim for clinicians is to search a predictive indicator in order to identify patients who are best suited for different therapy combination that thereby might increase the overall survival. Generally, potential predictive biomarkers include expression of oncogenes and tumor suppressor genes, markers of proliferation, angiogenesis, inflammation as well as regulation of genes involved in modulating the response to radiotherapy and chemotherapy. Of all the genes distinguished till date, operative oncogene Kirsten-ras (KRAS) (Kirsten Rat Sarcoma Viral Oncogene Homolog) and inoperative tumor suppressor genes like p53 and APC are found to be particularly important determinants of tumor incorporation and progression. KRAS gene is detected on the short arm of chromosome 12 ; encoding a $21 \mathrm{kD}$ protein required in $\mathrm{G}$ protein mediated signal transduction. It has constitutive GTPase activity, which gets neglected when the gene is mutated. $K R A S$ mutations will promote increased and uncontrolled cellular proliferation, and malignant transformation [1]. The KRAS protein is turned out to be operative transiently as a response to extracellular signals such as cytokines, growth factors and hormones that trigger cell surface receptors [4]. One of the most important targets is the epidermal growth factor receptor (EGFR) which is found to be activated in colorectal carcinogenesis by the binding of ligand to its outer surface [5]. The ligand binding to the outer part of EGFR results phosphorylation of tyrosine kinase domain situated in its inner part. Then, the receptor gets activated by promoting the activation of intracellular effectors involved in intracellular signaling pathways [5]. Following the identification of two anti-epidermal growth factor receptor (EGFR)-targeted antibodies, cetuximab (Erbitux) and panitumumab (Vectibix), the treatment of CRC has stepped into the world of personalized therapies. Bevacizumab (Avastin) is another monoclonal antibody that hinders vascular endothelial growth factor-A (VEGF-A) which has been reported to be involved in certain metastatic cancers [6]. Out of these three antibodies, cetuximab is a human-mouse chimeric $\operatorname{IgG}_{1}$ monoclonal antibody which was approved as a second-line therapy for CRC by Food and Drug Administration (FDA) in 2004. Panitumumab is a human $\operatorname{IgG}_{2}$ (Immunoglobulin $\mathrm{G}_{2}$ ) monoclonal antibody which was approved as a thirdline drug in 2007 by FDA [7]. The recombinant humanized monoclonal antibody, bevacizumab was approved in 2004 to combine with standard chemotherapy for metastatic CRC (mCRC). All the three antibody therapies are being used for the treatment of CRC considering the limitation of individual therapeutics. A comparative study is needed to highlight the most effective therapy among the different therapeutics. Considering the importance of KRAS gene mutation in CRC, an attempt is made in this review to highlight survival beneficial therapy for the CRC patients and the corresponding mostly cost effective.

\section{Inclusion and exclusion criteria}

Studies were eligible for inclusion if they reported data from already existing databases, cross-sectional studies, case series, case-control studies, or studies with a historical control or a cohort design. Studies were desirable for inclusion if they reported on a series of patients who underwent antibody therapy alone and the combination of antibody with chemotherapy, as well as progression free survival and overall survival parameters were analyzed in the sections of "material and methods" and "results". All studies eligible for inclusion in this review reported detailed information on the methods used to assess progression free survival (PFS) as well as overall survival (OS) parameters. When studies reported (partially) similar patient data, only the most recent and complete data sets were considered.

\section{Search strategy}

Medline database used in our study (January 2000 to December 2016) was searched with the help of a clinical librarian. The keywords and medical subject headings (MeSH) used were "colorectal cancer", "KRAS mutation", "antibody therapy" and "FOLFOX-4" as indicated in Table 1. Only the clinical studies reported in English were selected. A manual cross-reference search of the desirable papers was performed to find additional relevant articles. Based on the primary search results, the researchers independently selected the studies that matched the inclusion criteria. Data recited as unpublished and data from the abstracts were not utilized. Any disagreements between the researchers with respect to the studies which should be included were rectified through discussion.

\section{Data extraction}

Data were extracted only from original articles using a preformatted sheet with a set of predefined 
MeSH and free text words

("FOLFOX4 protocol", OR "Folfox regimen", OR "FOLFOX-4 protocol”, OR "Folinic Acid-SF”, OR "Folinic Acid SF”, OR "Leukovorin", OR "Leukovorum", OR "Folinic Acid”, OR “Acid, Folinic", OR "Leucovorin, (DL)-Isomer", OR "Calcium Leucovorin", OR "Leucovorin, Calcium", OR "Calcium Folinate" OR "5FU”, OR "5-FU”, OR "5-Fluorouracil”, OR "5 Fluorouracil", OR "Fluoruracil", OR "5-FU Lederle" OR "5-FU medac", OR "5 FU medac" OR "Adrucil", OR "Flurodex", OR "Oxaliplatin) AND ("K-ras mutation") AND ("Antibodies, Monoclonal, Humanized", OR "Panitumumab", OR "Cetuximab", Or "Bevacizumab") AND ("Colorectal Neoplasms", OR "Colorectal cancer").

parameters: type of cancer and mutation, number of patients, drug administered, drug dosage, use period, patient PFS and OS.

\section{Statistics}

A statistician was consulted to evaluate the accuracy of our analysis. RevMan 5 was used to process the data and perform the analysis. Meta-analysis of the progression free survival and overall survival was attempted for studies presenting PFS and OS results obtained from patient's undergone with antibody therapy alone as well as antibody therapy in combination with chemotherapy. The results were presented as weighted mean differences [95\% confidence interval $(\mathrm{CI})] . P<0.05$ was considered to indicate that the results were significant.

\section{RESULTS}

\section{Study selection, characteristics of the studies}

The selection of studies according to the PRISMA flow diagram is outlined in Figure 1. Six full text articles published during 2000-2016 were screened for the review and meta-analysis among which all the studies had more than 10 patients. The details of the articles are listed in Table 2 .

\section{$K R A S$ mutation and antibody therapy for $\mathrm{CRC}$}

$K R A S$, as a proto-oncogene, is found to be mutated rapidly in $\mathrm{CRC}$ and has been linked with incorporation and progression of CRC [8]. In 2008, Amado et al. [9]

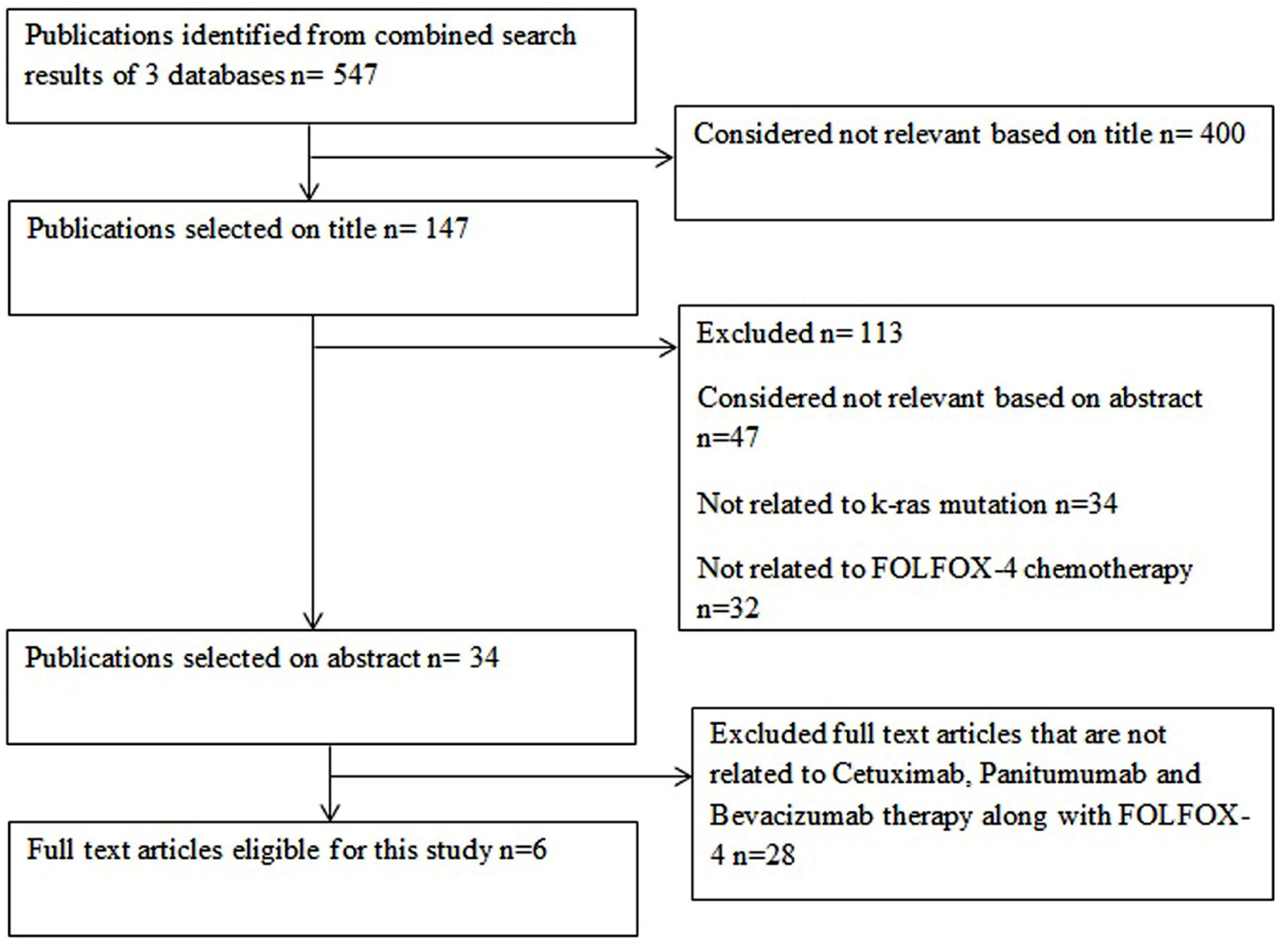

Figure 1: PRISMA flowchart for article screening (example). 
evaluated the anticipative role of $K R A S$ in the randomized experiment comparing panitumumab mono therapy with best supportive care and also determined whether the effect of panitumumab mono therapy on PFS differed between patients with wild (WT) and mutant (MT) type of KRAS. Douillard et al. [10] (2010) compared panitumumab-FOLFOX-4 therapy with FOLFOX-4 alone in WT KRAS and MT KRAS. Again in 2013, comparison of panitumumab-FOLFOX-4 therapy with $W T$ versus $M T K R A S$ was performed [11]. Sharma et al. [12] (2010) assessed the response and survival in mCRC patients after treating FOLFOX-4 individually and combined with bevacizumab. In 2008, Karapetis et al. [13] analysed tumor samples, obtained from 394 out of 572 patients with CRC who were randomly allocated to receive cetuximab. Bokemeyer et al. [14-15] (2009) evaluated whether the best overall response rate (ORR) of cetuximab FOLFOX-4 therapy was superior to that of FOLFOX-4 alone as first line treatment for mCRC. It has been reported that FOLFOX-4 was associated with better response rate, improved median survival and longer time for progression [16]. A recent study was done by Bencsikova et al. [17] (2015) on 1622 mCRC patients treated with bevacizumab along with oxaliplatin or irinotecan-based chemotherapy to monitor corresponding treatment outcomes with KRAS mutation status. Likewise, several randomized studies have been attempted to identify the efficacy of antibody therapy that adds up more benefits in CRC patients in combination with chemotherapy. Detail of medications administered and period of use are tabulated in Table 3.

\section{Effect of bevacizumab-FOLFOX-4 combination therapy on OS and PFS in CRC patients}

Sharma et al. [12] in 2010evaluated patients with mCRC treated with first-line FOLFOX-4 with or without bevacizumab. Out of $181 \mathrm{mCRC}$ patients, 83 received first-line FOLFOX-4 with or without bevacizumab and were evaluated for response. Among these patients, 44 out of 53 and 24 out of 30 received bevacizumab in combination with FOLFOX-4 in the WT KRAS and MT $K R A S$, respectively. In this study, no advantages were reported in the case of $M T K R A S$ in terms of response or progression free survival with FOLFOX-4 based chemotherapy. Bencsikova et al. [17] (2015) reported a significant study on 1622 patients with mCRC who were treated with bevacizumab plus oxaliplatin or irinotecan based chemotherapy. This study suggested that $M T$ $K R A S$ does not interfere with clinical benefit from firstline treatment with bevacizumab plus chemotherapy in mCRC patients. In this study, the overall survival was found to be improved in patients treated with the first line of bevacizumab with oxaliplatin as compared to irinotecan-based chemotherapy. Patients presenting with synchronous metastases had shorter OS, and subgroup analysis showed the significance of this effect was limited to WT KRAS subgroup. Similar to PFS, presence of multiple metastatic sites was the risk factor for shorter OS. KRAS subgroup analysis of clinical outcome in the context of chemotherapy back bone confirmed similar PFS in patients treated with bevacizumab/ oxaliplatin-based or bevacizumab/irinotecan based with or without $K R A S$ mutation. For patients with $W T$ $K R A S$ tumors, median OS was found to be 31.0 months in bevacizumab/oxaliplatin-based subgroup and about 29.2 months in case of bevacizumab/irinotecan-based first line treatment. Whereas in patients with $K R A S$ mutation, median OS was found to be 29.1 months for bevacizumab/oxaliplatin-based treatment and about 24.2 months for bevacizumab/irinotecan-based subgroup. Thus, it improved OS in patients who were started with bevacizumab plus XELOX or FOLFOX-4 which may be explained by shorter OS in MT KRAS patients. Sharma et al. [12] (2010) attempted to distinguish the PFS of WT KRAS and KRAS mCRC patients treated with first-line FOLFOX-4 (with or without bevacizumab) chemotherapy. The best ORR was $56.6 \%$ in WT KRAS and $50 \%$ in $M T K R A S$ patients. The median PFS was about 9.3 months in WT KRAS and 8.7 months in $M T$ $K R A S$ populations. Median OS rate was found to be 34.8 months in WTKRAS was not achieved in mCRC patients. Bevacizumab remains to be investigational yet and these data do not support any predictive role for $K R A S$ metastasis in response to FOLFOX-4 first-line chemotherapy.

\section{Effect of panitumumab and FOLFOX-4 therapy on OS and PFS in CRC patients}

Previous study by Amado et al. [9] (2008) in CRC with the help of antibody therapies and chemotherapy described the predictive part of KRAS in the randomized experiment comparing panitumumab mono therapy with best supportive care (BSC). Out of 463 patients originally enrolled, 231 patients are randomly allocated to panitumumab and BSC and 232 patients were randomly allocated to BSC. Among the 231 patients, 84 of them had MT KRAS and 124 of them had WT $K R A S$. In the other group, out of the 232 patients, 100 of them were found to have MT KRAS and 119 of them were found to have WT KRAS. It was found that patients with $W T K R A S$ had better PFS compared to patients with MT KRAS. Douillard et al. [10] in 2010 compared panitumumab-FOLFOX-4 therapy with FOLFOX-4 therapy in $W T$ and MT KRAS. Of the total 1183 patients, $593(\sim 50 \%)$ were randomly allocated to receive panitumumab-FOLFOX-4 and $590(50 \%)$ were allocated to receive FOLFOX-4 alone. This study revealed that in the WT KRAS, panitumumab-FOLFOX-4 significantly improved PFS compared with FOLFOX-4 alone. In 2013, another study reported comparison of 
Table 2: Characteristics of the studies

\begin{tabular}{|c|c|c|c|c|c|c|c|c|c|c|c|}
\hline 竧 & Ë & 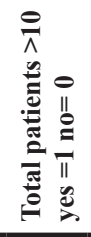 & 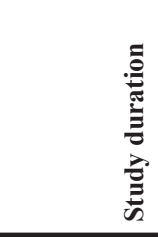 & 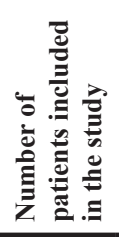 & 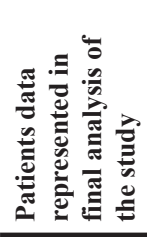 & 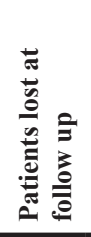 & 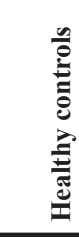 & 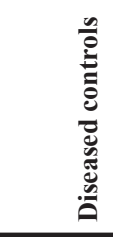 & & & 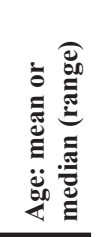 \\
\hline $\begin{array}{l}\text { Amado et al. [9] } \\
2008\end{array}$ & USA & 1 & NM & 463 & 427 & NM & No & No & $\begin{array}{l}\text { WT KRAS } \\
\text { PAN 62.5(29-82 })^{\#} \\
\text { BSC 63(32-81) }\end{array}$ & $\begin{array}{l}\text { MT KRAS } \\
\text { PAN 62(27-79) } \\
\text { BSC 62 }(27-83)^{\#}\end{array}$ & \\
\hline $\begin{array}{l}\text { Douillard et al. } \\
{[10]} \\
\mathbf{2 0 1 0}\end{array}$ & France & 1 & 2006-2008 & 1183 & 1096 & NM & No & No & $\begin{array}{l}\text { FOLFOX-4 } \\
61(24-82)^{\#} \\
\text { PAN+FOLFOX-4 } \\
62(27-85)^{\#}\end{array}$ & $\begin{array}{l}\text { FOLFOX-4 } \\
61(27-82)^{\#} \\
\text { PAN+FOLFOX-4 } \\
63(33-83)^{\#}\end{array}$ & \\
\hline $\begin{array}{l}\text { Douillard et al. } \\
{[11]} \\
\mathbf{2 0 1 3}\end{array}$ & France & 1 & NM & 1183 & 1060 & NM & No & No & NM & NM & \\
\hline $\begin{array}{l}\text { Karapetis et al. } \\
{[13]} \\
\mathbf{2 0 0 8}\end{array}$ & Australia & 1 & 2003-2005 & 572 & 394 & NM & No & No & $\begin{array}{l}\text { CTX } \\
63.5(28.6-85.9)^{\#}\end{array}$ & $\begin{array}{l}\text { CTX } \\
62(37.4-88.1)^{\#}\end{array}$ & \\
\hline $\begin{array}{l}\text { Bokemeyer et } \\
\text { al. [14] } \\
2009\end{array}$ & Germany & 1 & 2005-2006 & 344 & 337 & NM & No & No & $\begin{array}{l}\text { FOLFOX-4 } \\
59(36-82)^{\#} \\
\text { CTX+FOLFOX-4 } \\
59(24-74)^{\#}\end{array}$ & $\begin{array}{l}\text { FOLFOX-4 } \\
61(30-75)^{\#} \\
\text { CTX+FOLFOX-4 } \\
60(41-82)^{\#}\end{array}$ & \\
\hline $\begin{array}{l}\text { Bencsikova et } \\
\text { al. [17] } \\
2015\end{array}$ & Europe & 1 & 2005-2013 & 1622 & 1622 & NM & No & No & $\begin{array}{l}\text { BEV } \\
61(22-85)^{\#}\end{array}$ & $\begin{array}{l}\text { BEV } \\
63(22-83)^{\#}\end{array}$ & \\
\hline $\begin{array}{l}\text { Sharma et al. } \\
{[12]} \\
2010\end{array}$ & USA & 1 & 2008-2009 & 191 & 181 & NM & No & No & NM & NM & \\
\hline
\end{tabular}

Mean $={ }^{*}$ Median $={ }^{*}$ WT- Wild type; MT- Mutant; PAN- Panitumumab; BSC-Best Supportive Care ; CTX- Cetuximab; NM- Not mentioned; CRCColorectal cancer; Bev-Bevacizumab Disease type: CRC.

panitumumab-FOLFOX-4 therapy with $W T$ and $M T$ $K R A S$, where out of 1060 patients, 512 (48\%) were identified to have $W T K R A S$ and 548 (52\%) were identified to have $M T K R A S$ [11]. These patients were subjected to receive panitumumab plus FOLFOX-4 and inferred that improvements in overall survival rate was observed in WT KRAS. With KRAS mutation, there was a lack of response for panitumumab-FOLFOX-4 therapy [11]. In 2010, Douillard et al. [10] observed in $W T K R A S$ patients, the median PFS was about 9.6 months for panitumumab along with FOLFOX-4 and for OS it was about 23.9 months. The median progression free survival for FOLFOX-4 alone was found to be 8.0 months and the overall survival was about 19.7 months. In $M T K R A S$, the median OS was about 15.5 months for panitumumab-FOLFOX-4 combination and about 19.3 months for FOLFOX-4 alone. Douillard et al. [11] again in 2013 performed a study on 512 patients without $K R A S$ mutations in which PFS was found to be 10.1 months for panitumumab-FOLFOX-4 combination and 7.9 months for FOLFOX-4 alone. The OS was about 26.0 months in the panitumumab-FOLFOX-4 group whereas it was about 20.2 months for group treated with FOLFOX-4 alone. A total of 108 patients with WT KRAS exon 2 had other RAS mutations and these mutations were linked with inferior PFS and OS with panitumumab-FOLFOX-4 therapy, which was consistent with the findings in patients with KRAS mutations in exon 2.

\section{Effect of cetuximab and FOLFOX-4 therapy on OS and PFS in CRC patients}

Karapetis et al. [13] (2008) analysed tumor samples, obtained from 394 out of 572 patients with CRC who were randomly allocated to receive cetuximab and it was identified that MT KRAS did not benefit from cetuximab, whereas $W T K R A S$ got benefit from cetuximab. Bokemeyer et al. [14-15] in 2009 estimated whether the best ORR of cetuximab combined with FOLFOX-4 was superior to that of FOLFOX-4 alone as first line therapy with mCRC. In this study, 169 patients received cetuximab plus-FOLFOX-4 combination and 168 patients received FOLFOX-4 alone. MT KRAS was found in 233 out of 337 patients, 113 and 120 of them had received cetuximab plus FOLFOX-4 and FOLFOX-4 alone, respectively. This study demonstrated that addition of cetuximab to FOLFOX-4 increased the ORR compared with FOLFOX-4 alone. 
Bokemeyer et al. [14-15] (2009) confirmed the ORR of cetuximab plus-FOLFOX-4 combination which was superior to that of FOLFOX-4 alone. CetuximabFOLFOX-4 combination therapy was associated with a $43 \%$ reduction in the risk of progression in patients with WT KRAS. Lower risk of disease progression was observed in patients with WT KRAS, compared to MT $K R A S$ for cetuximab-FOLFOX-4combination therapy. The median PFS of WT KRAS with cetuximab alone was about 7.2 months and PFS of WT KRAS with cetuximab plus FOLFOX-4 was found to be 7.7 months. For KRAS mutation, PFS of cetuximab alone was found to be 8.6 months and cetuximab-FOLFOX-4combination was found to be 5.5 months. The detailed data of quality of life, safety, antibody testing of patients with WT KRAS and MT KRAS are summarized in Supplementary Table 1A. Data on PFS and OS for WT and MT KRAS are presented in Supplementary Table 1B.

\section{Meta-analysis for wild type and mutant type KRAS}

A meta-analysis was attempted to find out the efficacy of cancer therapy between PFS and OS patients in WT and MT KRAS. For the analysis, the hazard ratio (HR) and standard error (SE) with 95\% CI for antibodies, chemotherapy and combination of both were calculated. The $Q$-test statistic was determined to examine heterogeneity between trials. In addition, the $\mathrm{I}^{2}$ value, representing the percentage of total variability attributed to between study heterogeneity was calculated using RevMan 5. We would like to acknowledge the Cochrane community for providing it as free software to perform the forest plot analysis for this study.

A comparative study for PFS and OS of the WT and MT KRAS colorectal cancer patients has been done with antibody therapy (panitumumab, cetuximab and
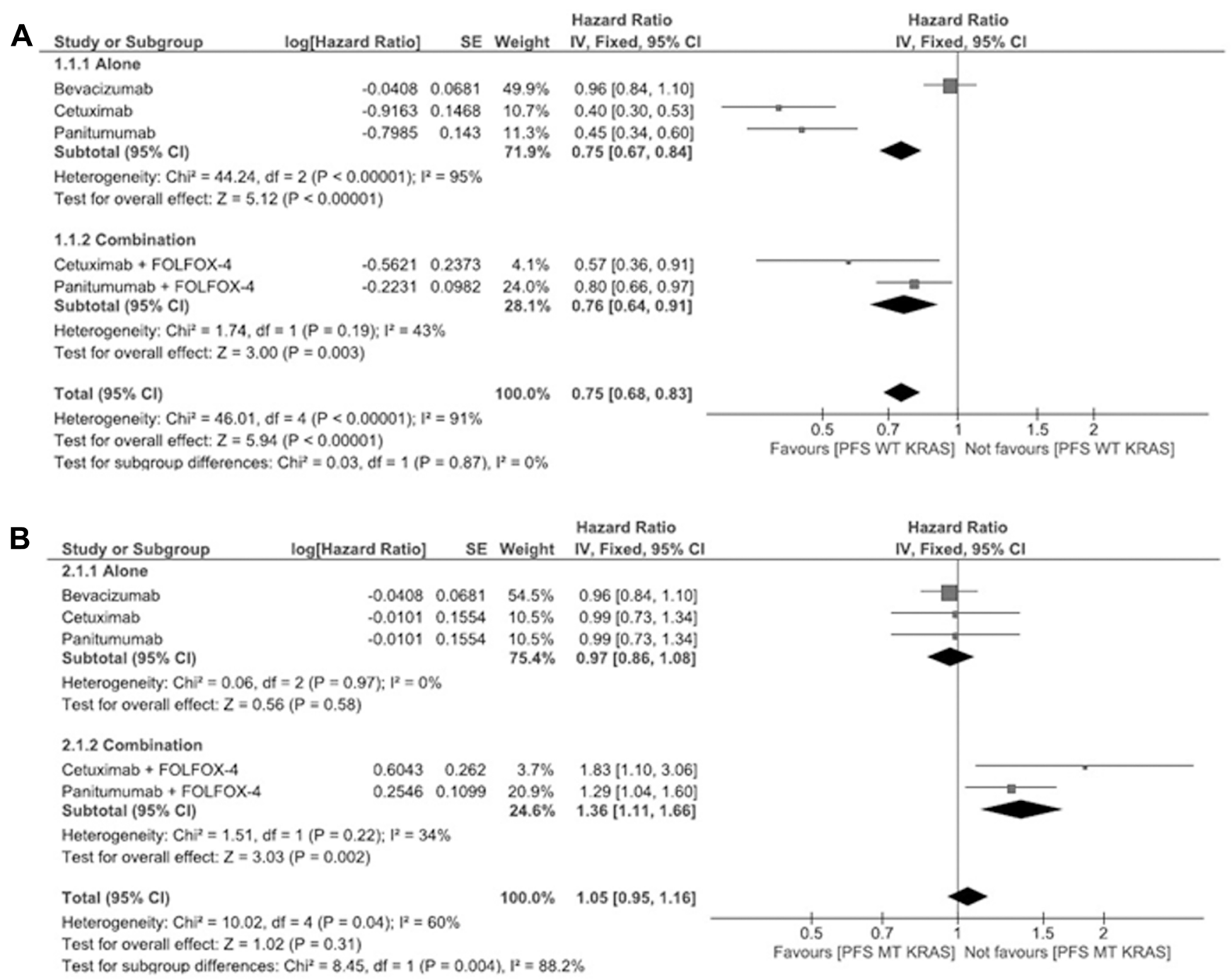

Figure 2: (A) Meta-analysis for wild type progression free survival of panitumumab, bevacizumab and cetuximab antibody therapies alone or in combination with FOLFOX-4 (for panitumumab and cetuximab). (B) Meta-analysis for mutant type progression free survival of panitumumab, bevacizumab and cetuximab antibody therapies alone or in combination with FOLFOX-4 (for panitumumab and cetuximab). 
bevacizumab) alone along with the combination of antibody and chemotherapy (FOLFOX-4).

The PFS for WT KRAS is shown in Figure 2A. In this plot, however the sample size seems to be limited; the antibody therapy shows effective treatment when compared to the combination therapy. In this analysis, the total HR for PFS with antibody therapy is $0.75(95 \%$ CI 0.67-0.84), whereas for the combinational therapy, the total HR for PFS being 0.76 (95\% CI 0.64-0.91). Thus, the response favors antibody therapy rather than the combination of antibody plus FOLFOX-4 therapy. The PFS for MT KRAS is shown in Figure 2B. The result depicts that the combination of antibody plus FOLFOX-4 shows reduced effectiveness, the total HR for PFS being 0.97 (95\% CI 0.86-1.08) with antibodies alone and 1.36 (95\% CI 1.11-1.66) for combination therapy respectively.

The OS for WT KRAS is shown in Figure 3A. The pooled HR for OS with antibody therapy in $W T$
KRAS patients is 0.74 (95\% CI $0.65-0.83)$ whereas for combinational therapy the pooled HR being 0.91 (95\% CI 0.74-1.12). Furthermore, the OS for panitumumab plus FOLFOX-4 patients shows enhanced effect, the pooled HR being 0.83 (95\% CI 0.67-1.03).

The OS for MT KRAS is shown in Figure 3B. This plot depicts that antibody therapies work better when compared to combination therapy. The pooled HR for OS with antibody therapy in $M T K R A S$ patients is 0.80 (95\% CI 0.71-0.91) whereas for combinational therapy the pooled HR is 1.16 (95\% CI 0.92-1.45).

Furthermore, the OS for panitumumab plus FOLFOX-4 patients shows enhanced effect, for both $W T$ and $M T$ KRAS when compared to other antibody therapies. The pooled HR for WT KRAS is 0.67 (95\% CI $0.55-0.82)$ and for $M T K R A S$ is 0.67 (95\% CI $0.55-0.82)$.

From the meta-analysis results (Figures 2A-2B and $3 \mathrm{~A}-3 \mathrm{~B}$ ) it shows that panitumumab and FOLFOX-4
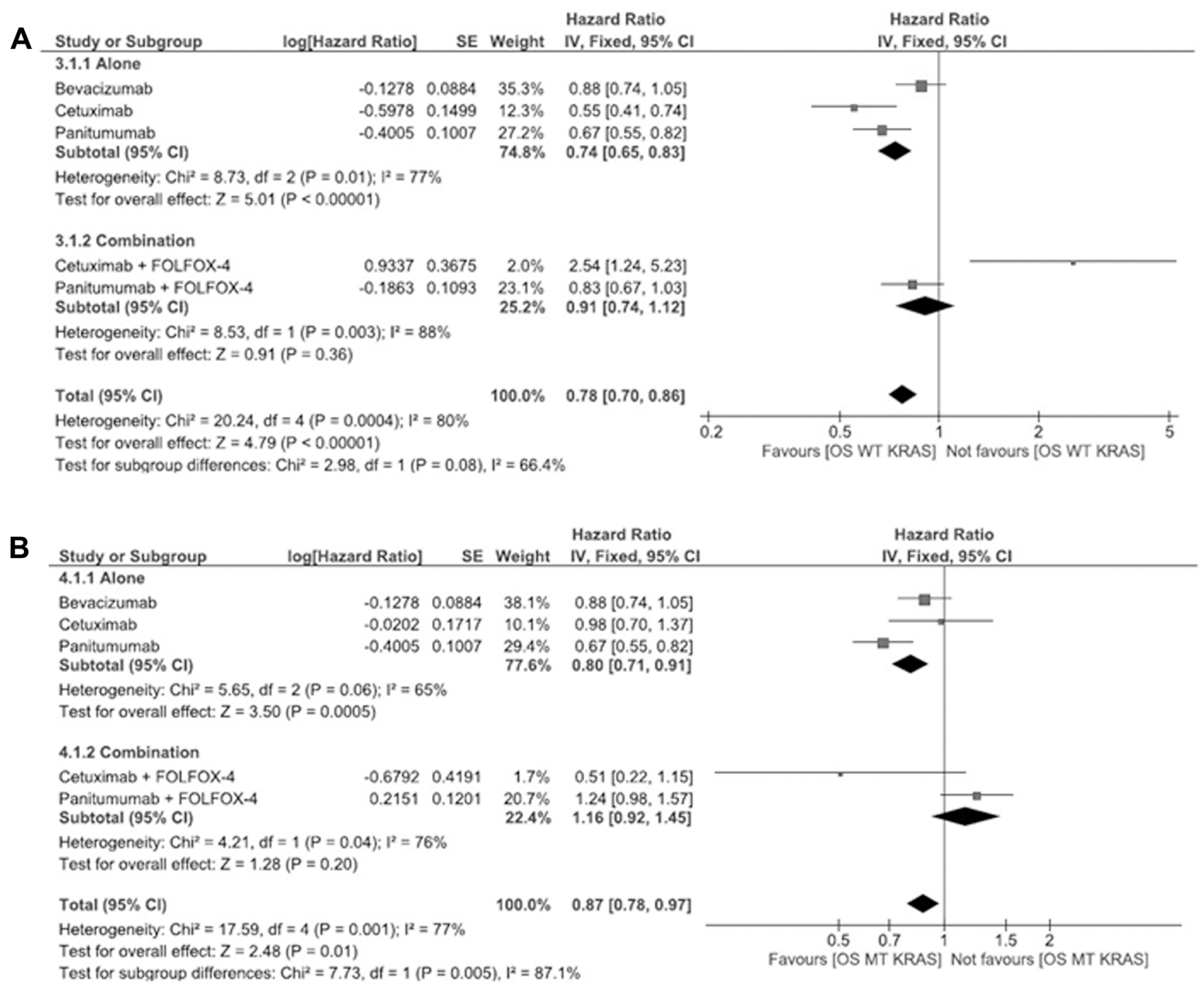

Figure 3: (A) Meta-analysis for wild type overall survival of panitumumab, bevacizumab and cetuximab antibody therapies alone or in combination with FOLFOX-4 (for panitumumab and cetuximab). (B) Meta-analysis for mutant type overall survival of panitumumab, bevacizumab and cetuximab antibody therapies alone or in combination with FOLFOX-4 (for panitumumab and cetuximab). 
Table 3: Type of medications, dose administered for the patients.

\begin{tabular}{|c|c|c|c|c|c|c|c|c|c|c|}
\hline 1st author & $\begin{array}{l}\text { BSC (No. of } \\
\text { patients) }\end{array}$ & $\begin{array}{l}\text { FOLFOX-4 } \\
\text { (No. of } \\
\text { patients) }\end{array}$ & $\begin{array}{l}\text { CTX } \\
+ \text { BSC } \\
\text { (No. of } \\
\text { patients) }\end{array}$ & $\begin{array}{l}\text { CTX + } \\
\text { FOLFOX-4 } \\
\text { (No. of patients) }\end{array}$ & $\begin{array}{l}\text { PAN + } \\
\text { FOLFOX-4 } \\
\text { (No. of } \\
\text { patients) }\end{array}$ & $\begin{array}{l}\text { BEV+ } \\
\text { FOLFOX-4 } \\
\text { (No.of } \\
\text { patients) }\end{array}$ & $\begin{array}{l}\text { FOLFOX-4 } \\
\text { dose }\end{array}$ & $\begin{array}{l}\text { CTX + } \\
\text { FOLFOX-4 } \\
\text { dose }\end{array}$ & PAN + FOLFOX-4 dose & $\begin{array}{l}\text { BEV+ } \\
\text { FOLFOX-4 } \\
\text { dose }\end{array}$ \\
\hline $\begin{array}{l}\text { Amado et } \\
\text { al.[9] } \\
2008\end{array}$ & $\begin{array}{l}\text { WT K-RAS } \\
119 \\
\text { MT K-RAS } \\
100\end{array}$ & - & - & - & - & & - & - & - & - \\
\hline $\begin{array}{l}\text { Doulliard et } \\
\text { al.[10] } \\
2010\end{array}$ & - & $\begin{array}{l}\text { WT K-RAS } \\
331 \\
\text { MT K-RAS } \\
219\end{array}$ & - & - & $\begin{array}{l}\text { WT K-RAS } \\
325 \\
\text { MT K-RAS } \\
221\end{array}$ & & $\begin{array}{l}\text { WT K-RAS } \\
\text { OX-865 mg/m } \\
\text { FU- } 8618 \\
\mathrm{mg} / \mathrm{m}^{2} \\
\text { FU continuous } \\
\text { infusion } \\
13,229 \mathrm{mg} / \mathrm{m}^{2} \\
\text { MT K-RAS } \\
\text { OX } \\
856 \mathrm{mg} / \mathrm{m}^{2} \\
\text { FU- } 8711 \mathrm{mg} / \\
\mathrm{m} 2 \\
\text { FU continuous } \\
13,109 \mathrm{mg} / \mathrm{m}^{2}\end{array}$ & - & $\begin{array}{l}\text { WT K-RAS } \\
\text { PAN- } 62 \mathrm{mg} / \mathrm{kg} \\
\text { OX- } 859 \mathrm{mg} / \mathrm{m}^{2} \\
\text { LV-200 } \mathrm{mg} / \mathrm{m}^{2} \\
\text { FU: } 8627 \mathrm{mg} / \mathrm{m}^{2} ; \\
\text { continuous infusion } \\
13,484 \mathrm{mg} / \mathrm{m}^{2} \\
\text { MT K-RAS } \\
\text { PAN- } 57 \mathrm{mg} / \mathrm{kg} \\
\text { OX- } 824 \mathrm{mg} / \mathrm{m}^{2} \\
\text { FU- } 8294 \mathrm{mg} / \mathrm{m}^{2} \\
\text { FU continuous infusion } \\
12878 \mathrm{mg} / \mathrm{m}^{2}\end{array}$ & - \\
\hline $\begin{array}{l}\text { Karapetis et } \\
\text { al. [13] } \\
2008\end{array}$ & $285 / 572$ & - & $287 / 572$ & - & - & & - & - & - & - \\
\hline $\begin{array}{l}\text { Bokemeyer } \\
\text { et al. [14] } \\
2009\end{array}$ & - & $\begin{array}{l}\text { WT K-RAS } \\
73 / 134 \\
\text { MT K-RAS } \\
47 / 99\end{array}$ & - & $\begin{array}{l}\text { WT K-RAS } \\
61 / 134 \\
\text { MT K-RAS } \\
52 / 99\end{array}$ & - & & $\begin{array}{l}\text { OX- } 85 \mathrm{mg} / \mathrm{m}^{2} \\
\mathrm{LV}-200 \mathrm{mg} / \mathrm{m}^{2} \\
\text { FU- } 1000 \\
\mathrm{mg} / \mathrm{m}^{2}\end{array}$ & $\begin{array}{l}\text { CTX- } 650 \\
\mathrm{mg} / \mathrm{m}^{2} \\
\mathrm{OX}-85 \mathrm{mg} / \mathrm{m}^{2} \\
\mathrm{LV}-200 \mathrm{mg} / \mathrm{m}^{2} \\
\mathrm{FU}-1000 \\
\mathrm{mg} / \mathrm{m}^{2}\end{array}$ & - & - \\
\hline $\begin{array}{l}\text { Sharma et } \\
\text { al. [12] } \\
2010\end{array}$ & - & $83 / 181$ & - & - & - & $\begin{array}{l}\text { WT K-RAS } \\
44 / 53 \\
\text { MT K-RAS } \\
24 / 30\end{array}$ & $\begin{array}{l}\text { OX- } 85 \mathrm{mg} / \mathrm{m}^{2} \\
\text { LV- } 400 \mathrm{mg} / \mathrm{m}^{2} \\
\text { FU- } 400 \mathrm{mg} / \mathrm{m}^{2}\end{array}$ & - & - & $\begin{array}{l}\text { BEV- } 5 \mathrm{mg} / \mathrm{kg} \\
\text { OX- } 85 \mathrm{mg} / \mathrm{m}^{2} \\
\text { LV- } 400 \mathrm{mg} / \\
\mathrm{m}^{2} \\
\text { FU- } 400 \mathrm{mg} / \\
\mathrm{m}^{2}\end{array}$ \\
\hline
\end{tabular}

BSC-Best Supportive Care; WT-Wild type; MT-Mutant; OX-Oxaliplatin; LV-Leucovorin; FU-Fluorouracil; PAN-Panitumumab; CTX-Cetuximab; - No; NM-Not Mentioned

\section{Table 4: Cost effectiveness for various antibody treatments}

\begin{tabular}{ll}
\hline ANTIBODY THERAPY+CHEMOTHERAPY & COST EFFECTIVENESS \\
\hline 1. Panitumumab + FOLFOX-4 [18] & $\begin{array}{l}\text { Cost starts from } 40000 € . \\
\text { Panitumumab + FOLFOX added a good value for money. } \\
\text { 2. Bevacizumab + FOLFOX-4 [19] }\end{array}$ \\
$\begin{array}{l}\text { It has been equated to an incremental cost-effectiveness } \\
\text { ratio (ICER) of more than half a million dollars per } \\
\text { quality-adjusted life year. The use of the VEGF inhibitor } \\
\text { beyond progression had a cost-effectiveness ratio of } \\
\text { more than } \$ 350,000 .\end{array}$
\end{tabular}

3. Cetuximab + FOLFOX-4 [20]

It costs around $\$ 202484$.

combination is advantageous when considering the $W T$ $K R A S$ mutation, but panitumumab alone has enhanced effect when considering the MT KRAS patients evaluated for the HR in PFS and OS.

\section{Cost effectiveness}

Analysis of the cost of antibody therapies in combination with chemotherapy indicates that panitumumab-FOLFOX-4 combination represents the most cost-effective therapy compared to bevacizumab, where the minimum expense is $\sim 40000 €$. When bevacizumab is used as a first-line therapy for mCRC, it has been equated to an incremental cost-effectiveness ratio
(ICER) of more than half a million dollars per qualityadjusted life year. The use of the VEGF inhibitor beyond progression had a cost-effectiveness ratio more than $\$ 350,000$ whereas the FOLFOX-4 regimen plus cetuximab therapy costs $\$ 202484$. Thus, panitumumab therapy was found to be cost-effective when compared with its alternatives in the treatment of patients with un-resectable mCRC (Table 4) [18, 19, 20].

\section{CONCLUSIONS}

Various antibody therapies such as bevacizumab, panitumumab and cetuximab have become available for 
CRC treatment. These antibody therapies have been used individually or in combination with chemotherapy. This review brings out the most potential antibody therapy in combination with chemotherapy (specifically, FOLFOX-4 has been analysed in the current study). The metaanalysis shows that panitumumab with FOLFOX-4 is advantageous than the other two therapies considering PFS, OS and cost effectiveness as well for the patients with WT KRAS mutation. Hence, the results of this study portrays that $K R A S$ status might be used as a predictive factor in relation to the efficacy of antibody-chemotherapy and it highlights the increasing importance of tumor biomarker analysis as an element of therapy selection.

\section{Abbreviations}

CRC- Colorectal Cancer; mCRC- Metastatic Colorectal Cancer; PFS- Progression Free Survival; OSOverall Survival; GTPase- Guanosine Triphosphate; $\mathrm{IgG}_{2}-$ Immunoglobulin $\mathrm{G}_{2}$ FDA- Food and Drug Administration; EGFR- Epidermal Growth Factor Receptor; VEGF-A Vascular Endothelial Growth Factor A; KRAS- Kirsten RAS; $W T$ - Wild type; $M T$ - Mutant type; BSC- Best Supportive Care; ORR- Overall Response Rate; ICER- Incremental Cost Effectiveness Ratio; PRISMA-Preferred Reporting Items for Systematic Reviews and Meta-analyses; HRHazard Ratio; SE- Standard Error; CI- Class Interval.

\section{Author contributions}

Pathak S, Sun XF, Banerjee A, Zhang H, Marotta F designed the study. Pathak S, Sushmitha S, Bhavani $\mathrm{B}$, Gopinath $\mathrm{M}$ and Banerjee A wrote the manuscript. Murugesan $\mathrm{R}$ and Sushmitha $\mathrm{S}$ did the meta-analysis part and revised the MS. Girigoswami A and Sollano J read and revised the manuscript. All authors checked and approved the final manuscript.

\section{ACKNOWLEDGMENTS}

The authors are thankful to Chettinad Academy of Research and Education (CARE), Chennai, India and Department of Oncology, Linkoping University, Sweden for research facilities and Mr. Alexander, CARE for his initial help to understand the meta-analysis study.

\section{CONFLICTS OF INTEREST}

No potential conflicts of interest were disclosed.

\section{FUNDING}

This study was financially supported by grants from the Swedish Cancer Foundation, Swedish Research Council and the Health Research Council in the SouthEast of Sweden.

\section{REFERENCES}

1. Smith G, Carey FA, Beattie J, Wilkie MJ, Lightfoot TJ, Coxhead J, Garner RC, Steele RJ, Wolf CR. Mutations in APC, Kirsten-ras, and p53 - alternative genetic pathways to colorectal cancer. Proc Natl Acad Sci USA. 2002; 99:9433-38.

2. Schuebel KE, Chen W, Cope L, Glöckner SC, Suzuki H, Yi JM, Chan TA, Van Neste L, Van Criekinge W, van den Bosch S, van Engeland M, Ting AH, Jair K, et al. Comparing the DNA hypermethylome with gene mutations in human colorectal cancer. PLoS Genet. 2007; 3:1709-23.

3. Pathak S, Meng WJ, Zhang H, Gnosa S, Nandy SK, Adell G, Holmlund B, Sun XF. Tafazzin protein expression is associated with tumorigenesis and radiation response in rectal cancer: a study of Swedish clinical trial on preoperative radiotherapy. PLoS One. 2014; 9:e98317.

4. Brink M, de Goeij AF, Weijenberg MP, Roemen GM, Lentjes MH, Pachen MM, Smits KM, de Bruïne AP, Goldbohm RA, van den Brandt PA. K-ras oncogene mutations in sporadic colorectal cancer in The Netherlands Cohort Study. Carcinogenesis. 2003; 24:703-10.

5. Lièvre A, Bachet JB, Boige V, Cayre A, Le Corre D, Buc E, Ychou M, Bouché O, Landi B, Louvet C, André T, Bibeau F, Diebold MD, et al. KRAS mutations as an independent prognostic factor in patients with advanced colorectal cancer treated with cetuximab. J Clin Oncol. 2008; 26:374-79.

6. Los M, Roodhart JM, Voest EE. Target practice: lessons from phase III trials with bevacizumab and vatalanib in the treatment of advanced colorectal cancer. Oncologist. 2007; 12:443-50.

7. Tan $\mathrm{C}, \mathrm{Du} \mathrm{X}$. KRAS mutation testing in metastatic colorectal cancer. World J Gastroenterol. 2012; 18:5171-80.

8. Fearon ER, Vogelstein B. A genetic model for colorectal tumorigenesis. Cell. 1990; 61:759-67.

9. Amado RG, Wolf M, Peeters M, Van Cutsem E, Siena S, Freeman DJ, Juan T, Sikorski R, Suggs S, Radinsky R, Patterson SD, Chang DD. Wild-type KRAS is required for panitumumab efficacy in patients with metastatic colorectal cancer. J Clin Oncol. 2008; 26:1626-34.

10. Douillard JY, Siena S, Cassidy J, Tabernero J, Burkes R, Barugel M, Humblet Y, Bodoky G, Cunningham D, Jassem J, Rivera F, Kocákova I, Ruff P, et al. Randomized, phase III trial of panitumumab with infusional fluorouracil, leucovorin, and oxaliplatin (FOLFOX4) versus FOLFOX4 alone as first-line treatment in patients with previously untr eated metastatic colorectal cancer: the PRIME study. J Clin Oncol. 2010; 28:4697-705.

11. Douillard JY, Oliner KS, Siena S, Tabernero J, Burkes R, Barugel M, Humblet Y, Bodoky G, Cunningham D, Jassem J, Rivera F, Kocákova I, Ruff P, et al. PanitumumabFOLFOX4 treatment and RAS mutations in colorectal cancer. N Engl J Med. 2013; 369:1023-34.

12. Sharma N, Saifo M, Tamaskar IR, Bhuvaneswari R, Mashtare T, Fakih M. KRAS status and clinical outcome in metastatic colorectal cancer patients treated with first- 
line FOLFOX chemotherapy. J Gastrointest Oncol. 2010; 1:90-96.

13. Karapetis CS, Khambata-Ford S, Jonker DJ, O'Callaghan CJ, Tu D, Tebbutt NC, Simes RJ, Chalchal H, Shapiro JD, Robitaille S, Price TJ, Shepherd L, Au HJ, et al. $\mathrm{K}$-ras mutations and benefit from cetuximab in advanced colorectal cancer. N Engl J Med. 2008; 359:1757-65.

14. Bokemeyer C, Bondarenko I, Makhson A, Hartmann JT, Aparicio J, de Braud F, Donea S, Ludwig H, Schuch G, Stroh C, Loos AH, Zubel A, Koralewski P. Fluorouracil, leucovorin, and oxaliplatin with and without cetuximab in the first-line treatment of metastatic colorectal cancer. J Clin Oncol. 2009; 27:663-71.

15. Bokemeyer C, Bondarenko I, Hartmann JT, de Braud F, Schuch G, Zubel A, Celik I, Schlichting M, Koralewski P. Efficacy according to biomarker status of cetuximab plus FOLFOX-4 as first-line treatment for metastatic colorectal cancer: the OPUS study. Ann Oncol. 2011; 22:1535-46.

16. Gill S, Thomas RR, Goldberg RM. Review article: colorectal cancer chemotherapy. Aliment Pharmacol Ther. 2003; 18:683-92.
17. Bencsikova B, Bortlicek Z, Halamkova J, Ostrizkova L, Kiss I, Melichar B, Pavlik T, Dusek L, Valik D, Vyzula R, Zdrazilova-Dubska L. Efficacy of bevacizumab and chemotherapy in the first-line treatment of metastatic colorectal cancer: broadening KRAS-focused clinical view. BMC Gastroenterol. 2015; 15:37.

18. Graham CN, Hechmati G, Hjelmgren $\mathrm{J}$, de Liège $\mathrm{F}$, Lanier J, Knox H, Barber B. Cost-effectiveness analysis of panitumumab plus mFOLFOX6 compared with bevacizumab plus mFOLFOX6 for first-line treatment of patients with wild-type RAS metastatic colorectal cancer. Eur J Cancer. 2014; 50:2791-801.

19. Lawrence L. High Cost, Minimal Benefit for Bevacizumab in Metastatic CRC. Cancer Network. 2015.

20. Davari M, Ashrafi F, Maracy M, Aslani A, Tabatabaei M. Cost-effectiveness Analysis of Cetuximab in Treatment of Metastatic Colorectal Cancer in Iranian Pharmaceutical Market. Int J Prev Med. 2015; 6:63. 